\title{
PURWARUPA ALAT TELEMONITORING KEAMANAN RUANGAN MENGGUNAKAN IDENTIFIKASI SIDIK JARI BERBASIS INTERNET OF THINGS
}

\section{TELEMONITORING EQUIPMENT PROTOTYPE USING INTERNET OF THINGS BASED FINGERPRINT IDENTIFICATION}

\author{
Wahyu Kusuma Raharja ${ }^{1}$, Bagas Santoso ${ }^{2}$ \\ 1,2 Program Studi Teknik elektro, Universitas Gunadarma, Jakarta \\ ${ }^{1}$ wahyukr@staff.gunadarma.ac.id, ${ }^{2}$ bagussantosa03@gmail.com
}

\begin{abstract}
Abstrak
Kebutuhan manusia penyimpanan dokumen atau barang berharga memerlukan tempat yang mempunyai keamanan yang baik dari ulah orang lain dari pencurian. Tempat penyimpanan dapat berupa brangkas atau rungan Salah satu cara alat untuk meningkatkan keamanan ruangan disuatu bangunan dengan membuat alat monitoring yang dikendalikan dari jarak jauh menggunakan jaringan internet. Selain itu juga dapat menggunakan sensor sidik jari yang dapat mengidentifikasi user yang keluar atau masuk ruangan tersebut. Penelitian ini bertujan untuk menghasilkan prototipe sistem monitorinng keamanan ruangan dengan identifikasi sidik jari menggunakan jaringan internet untuk proses tranfer data pada web database. Alat dirancang dan dibangun menggunakan sensor sidik jari dan push button sebagai blok input, Arduino uno dan nodemcu esp8266 sebagai blok proses, motor servo, relay, solenoid dan LCD 16x2 sebagai output yang akan dihubungkan untuk membentuk sebuah rangkaian. Penelitian ini berhasil merancang dan membangun purwarupa alat monitoring keamanan ruangan menggunakan sidik jari berbasis internet of things. Hasil informasi rekam data pengguna ruangan yang ditampilkan pada website dengan alamat http://homeguard.000webhostapp.com/index.php Berdasarkan pengujian alat ini menggunakan sensor sidik jari dapat mendeteksi sidik jari baik yang sudah terdaftar maupun yang belum terdaftar. Hasil pengujjian delay waktu dari proses sensor pendeteksian sidik jari hingga informasi masuk dalam tampilan di website rata-rata sebesar 2,25 detik.
\end{abstract}

Kata kunci : telemonitoring keamanan ruangan, sensor sidik jari, nodemcu ESP8266, arduino uno, internet of things

\begin{abstract}
Human needs, storage of documents or valuables requires a place that has good security from the act of others from theft. The storage area can be in the form of a safe or room. One way to increase the security of the room in a building is by creating a monitoring tool that is controlled remotely using the internet network. In addition, you can also use a fingerprint sensor that can identify users who leave or enter the room. This study aims to produce a prototype room security monitoring system with fingerprint identification using the internet network for data transfer processes on a web database. The tool is designed and built using a fingerprint sensor and push button as an input block, Arduino uno and nodemcu esp8266 as a process block, servo motor, relay, solenoid and $16 \times 2$ LCD as outputs to be connected to form a circuit. This research succeeded in designing and building a room security monitoring tool prototype using fingerprints based on the internet of things. The results of room user data record information are displayed on the website with the address http://home-guard.000webhostapp.com/index.php. Based on the testing of this tool using a fingerprint sensor can detect fingerprints both registered and unregistered. The results of the time delay testing from the fingerprint detection sensor process until the information entered on the display on the website is an average of 2.25 seconds.
\end{abstract}

Keywords: security telemonitoring, fingerprint sensor, nodemcu ESP8266, arduino uno, internet of things 


\section{PENDAHULUAN}

Perkembangan TIK yang pesat dapat dimanfaatkan manusia untuk membantu aktifitas. Salah satu pemanfaatannya digunakan pada bidang keamanan. Pada bidang tersebut, sistem keamanan dapat mendeteksi identitas seseorang berdasar sensor biometrik dan memonitor aktifitas pada sistem tersebut, seperti waktu masuk dan keluar suatu ruangan, berapa lama sesorang aktifitas pada ruangan.

Sistem keamanan dengan sistem biometrik seperti penggunaan sidik jari dapat digunakan untuk verifikasi identitas seseorang, sehingga hanya orang yang sudah terdaftar pada database yang bisa melakukan akses masuk ruangan yang mempunyai privasi tinggi.

Penggunaan IOT (Internet of Things) yang merupakan sebuah konsep untuk memperluas manfaat dari konektivitas internet yang tersambung secara terus menerus yang digunakan untuk mentransfer data melalui jaringan. Selain itu dengan memannfaatkan database berbasis web dapat menyimpan identitas diri dan menangkap (capture) tampilan wajah seseorang atau user menggunakan kamera dan waktu masuk keluar dalam ruangan.

Beberapa penelitian yang berkaitan dengan pada sistem keamanan telah dilakukan, seperti penelitian [1,2] yang menggunakan RFID sebagai unit masukan pada sistem keamanan. Penelitian $[3,4]$ telah berhasil membangun sistem keamanan menggunakan sidik jari dan penekanan tombol keypad. Sistem keamanan yang telah dilakukan pada penelitian-penelitian tersebut masih belum memanfaatkan proses monotitoring menggunkan web database, sehingga belum merekam identitas user dan waktu keluar masuk ruangan.

Berdasarkan permasalahan tersebut, maka penelitian ini bertujuan untuk merancang dan membangun prototipe sistem monitorinng keamanan dengan identifikasi sidik jari menggunakan jaringan internet untuk proses tranfer data pada web database. Sistem yang dibangun dapat diterapkan pada sistem keamanan suatu rungan dengan privasi yang tinggi, sehingga dapat memonitor aktifitas ruangan tersebut oleh yang berwenang.

\section{DASAR TEORI /MATERIAL DAN METODOLOGI/PERANCANGAN}

\subsection{Tinjauan Pustaka}

Internet of Things (IoT)

IoT merupakan sebuah konsep yang bertujuan untuk memperluas manfaat dari konektivitas internet yang tersambung secara terus-menerus. Adapun kemampuan seperti berbagi data, remote control, dan sebagainya, termasuk juga pada benda di dunia nyata. Contohnya bahan pangan, elektronik, koleksi, peralatan apa saja, termasuk benda hidup yang semuanya tersambung ke jaringan lokal dan global melalui sensor yang tertanam dan selalu aktif.

Pada dasarnya, Internet of Thingss mengacu pada benda yang dapat diidentifikasikan secara unik sebagai representasi virtual dalam struktur berbasis Internet. Istilah Internet of Thingss awalnya disarankan oleh Kevin Ashton pada tahun 1999 dan mulai terkenal melalui Auto-ID Center di MIT.Dan kini IoT menjadi salah satu tugas bagi seorang mahasiswa di sebuah perguruan tinggi [5].

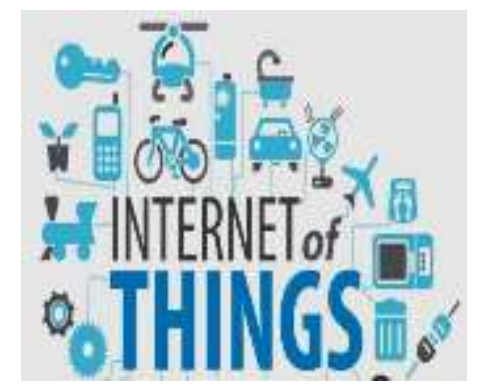

Gambar 1. Ilustrasi Dari Internet Of Things 


\section{Sensor Sidik Jari ZFM20}

ZFM20 series adalah modul identifikasi sidik jari terpisah yang mengambil Synochip DSP sebagai prosesor utama dan sensor optik. Modul ini melakukan serangkaian fungsi seperti pendaftaran sidik jari, pengolahan gambar, pencocokan sidik jari, serching dan penyimpanan template [6].

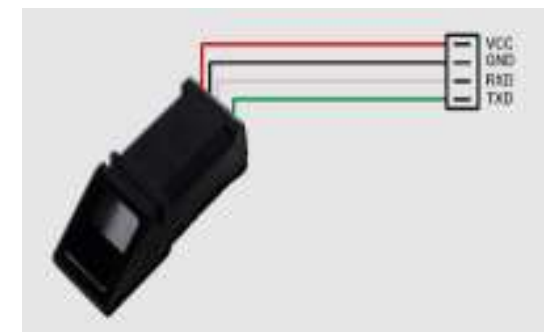

Gambar 2. Tampilan Fisik Sensor Sidik Jari ZFM20

Sistem sensor sidik jari membaca data yang selanjutnya digunakan sebagai verifikasi. Sensor sidik jari yang biasa digunakan untuk presensi, verifikasi password, manajemen akses atau perangkat mesin yang mengkombinasikan dengan perangkat kunci seperti akses kontrol menggunakan beberapa teknik pembacaan sidik jari.

Spesifikasi sensor sidik jari ZFM20 adalah sebagai berikut:

- Power: DC 3.6V-6.0V

- Working current Typical: 100mA Peak: $150 \mathrm{~mA}$

- Baud rate: $(9600 * N) b p s, N=1 \sim 12$ (default $N=6$ )

- Image acquiring time: $<1 s$

- Storage capacity: $120 / 375 / 880$

- FAR: $<0.001 \%$

- FRR: $<0.1 \%$

- Average searching time: < $1 s(1: 880)$

- Window dimension $14 \mathrm{~mm} * 18 \mathrm{~mm}$

- Working environment: Temp: $-10^{\circ} \mathrm{C}-+40^{\circ} \mathrm{C}$ RH: $40 \%-85 \%$

- Storage environment: Temp: $-40^{\circ} \mathrm{C}-+85^{\circ} \mathrm{CRH}:<85 \%$

- Outline Dimention: Split type Module: $42 * 25 * 8.5 \mathrm{~mm}$

- Interface: UART (TTL logicallevel)/ USB 1.1

- Matching Mode: 1:1 and 1:N

- Character file size: 256 bytes

- Template size: 512 bytes

- Security level 5: (1, 2, 3, 4, 5(highest))

\section{Arduino Uno}

Arduino adalah nama keluarga papan mikrokontroler yang awalnya dibuat oleh perusahaan Smart Projects. Salah satu tokoh penciptanya adalah Massimo Banzi. Papan ini merupakan perangkat keras yang bersifat open source. Arduino Uno adalah board mikrokontroler berbasis ATMEGA 328 memiliki 14 pin input dan output digital, dimana 6 pin input tersebut dapat digunakan sebagai output PWM dan 6 pin input analog, $16 \mathrm{MHz}$ osilator kristal, koneksi USB, jack power, ICSP header, dan tombol reset. Untuk mendukung mikrokontroler agar dapat digunakan, cukup hanya menghubungkan board Arduino Uno ke komputer dengan menggunakan kabel USB atau listrik AC dengan terlebih dahulu dihubungkan ke adaptor DC atau baterai untuk menjalankannya [7].

UNO berbeda dari semua papan sebelumnya dalam hal itu tidak menggunakan FTDI chip driver USB-to-serial. Sebaliknya, fitur Atmega16U2 (Atmega8U2 hingga versi R2) diprogram sebagai konverter USB-to-serial. Revisi 2 dari dewan UNO memiliki resistor menarik garis 8U2 HWB ke tanah, sehingga lebih mudah untuk dimasukkan ke dalam mode DFU. 


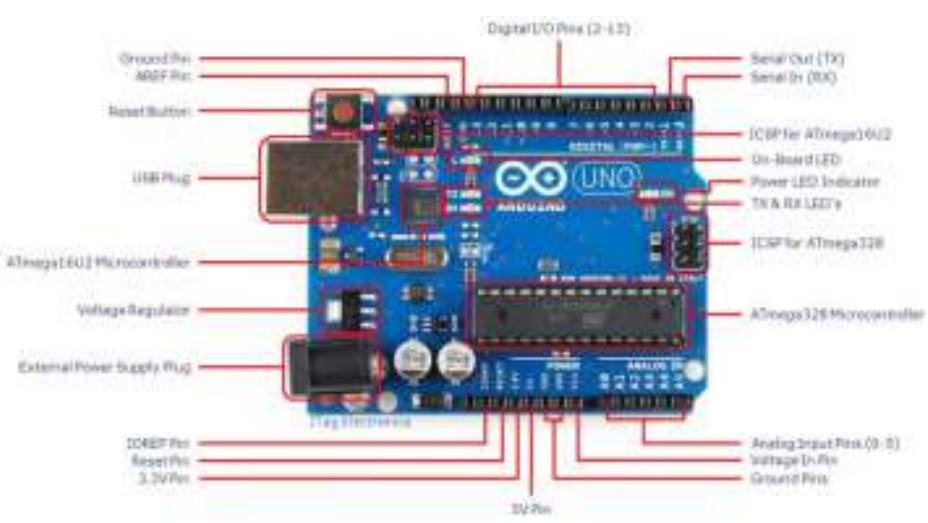

Gambar 3. Tampilan Fisik Arduino UNO

\section{NodeMCU ESP8266}

NodeMCU merupakan papan pengembangan produk Internet of Things (IoT) yang berbasiskan Firmware eLua dan System on a Chip (SoC) ESP8266-12E. ESP8266 sendiri merupakan chip WiFi dengan protocol stack TCP/IP yang lengkap.

[1] NodeMCU dapat dianalogikan sebagai board arduino-nya ESP8266. Program ESP8266 sedikit merepotkan karena diperlukan beberapa teknik wiring serta tambahan modul USB to serial untuk mengunduh program. Namun NodeMCU telah me-package ESP8266 ke dalam sebuah board yang kompak dengan berbagai fitur layaknya mikrokontroler + kapabilitas akses terhadap Wifi juga chip komunikasi USB to serial. Sehingga untuk memprogramnya hanya diperlukan ekstensi kabel data USB persis yang digunakan charging smarphone [8].

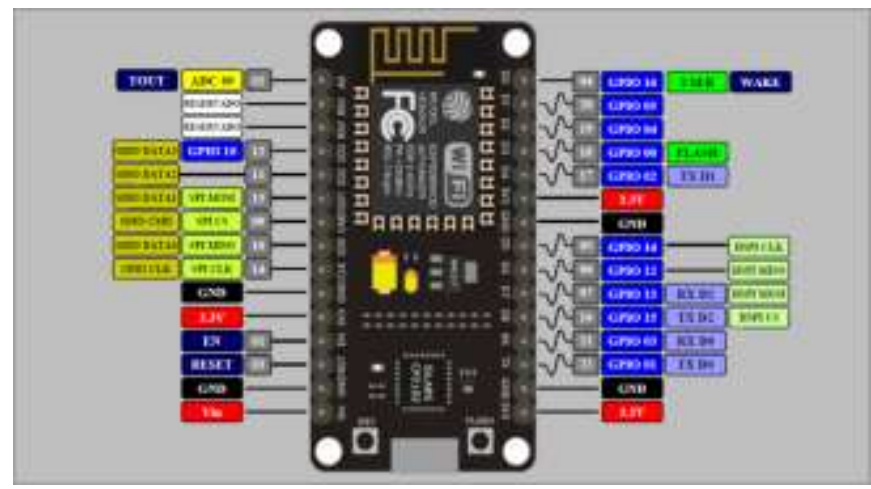

Gambar 4. Modul NodeMCU ESP8266

\section{I2C/TWI Connector}

I2C (Inter Integreated Circuit) adalah standar komunikasi serial dua arah menggunakan dua saluran yang didesain khusus untuk mengirim maupun menerima data. Sistem I2C/TWI terdiri dari saluran SCL (Serial Clock) dan SDA (Serial Data) yang membawa informasi data antara I2C dengan pengontrolnya serta pull up resistor yang digunakan untuk transfer data antar perangkat. I2C/TWI juga merupakan transmisi serial setengah duplex oleh karena itu aliran data dapat diarahkan pada satu waktu. Tingkat transfer data mengacu pada sinyal clock pada SCL Bus 1/16th slave. informasi data antara I2C dengan pengontrolnya. Piranti yang dihubungkan dengan sistem I2C Bus dapat dioperasikan sebagai Master dan Slave. Master adalah piranti yang memulai transfer data pada I2C Bus dengan membentuk sinyal Start, mengakhiri transfer data dengan membentuk sinyal Stop dan membangkitkan sinyal clock. Slave adalah piranti yang dialamati master [10]. 


\subsection{Metodologi Penelitian}

Penelitian ini dilakukan dengan langkah-langkah sebagai berikut:

\section{Studi Literatur}

Tahap ini diperlukan untuk mengambil sumber-sumber informasi yang diperlukan dalam penelitian ini. Bahan kajian terdiri dari buku referensi, data sheet, jurnal, dan informasi yang bersumber dari internet.

\section{Perancangan}

Tahap ini terdiri dari perancangan pernagkat keras dan perangkat lunak. Perancangan perangkat keras dengan membuat blok diagram komponen-komponen yang diperlukan dengan susunan hubungan blok input, proses, dan output. Perancangan perangkat lunak dengan membuat diagram alir pemrograman yang akan ditanamkan pada modul arduino uno.

\section{Pembuatan Dan Pengujian Alat}

Pada metode ini merupakan suatu pembuatan alat dari bahan-bahan dan komponenkomponen yang telah dikumpulkan menjadi sebuah alat sampai dengan program yang digunakan. Kemudian dilakukan pengujian alat dengan cara mengetahui masing-masing jalan kerja dari rangkaian alat yang digunakan agar tidak terjadi kesalahan.

\section{Pembahasan}

Setelah hasil-hasil data pengujian diperoleh, selanjutnya dilakukan pembahasan pada data yang telah didapatkan berdasarkan teori dan datasheet dari komponen yang dipakai, serta keakuratan kinerja dari alat yang telah dibangun.

\subsection{Perancangan Perangkat Keras}

Rancangan susunan komponen-komponen dalam membangun alat pada penelitian ini diperlihatkan pada gambar 5. Suusnan blok diagram terdiri dari blok input, proses, dan output.

Blok masukan (iinput) menggunakan sensor sidik jari dan push button. Sensor sidik jari digunakan untuk mendeteksi identitas sesorang yang memasuki ruangan yang selanjutnya data identitas orang tersebut akan diproses oleh blok proses, apakah orang tersebut dibukakan pintu atau tidak. Komponen push button sebagai tombol kontrol untuk membuka pintu dari dalam ruangan.

Blok proses menggunkan modul kit Arduino Uno dan Module NodeMcu ESP8266. Arduino Uno berfungsi untuk memproses data yang diperoleh dari sinyal sensor sidik jari dan mengontol blok output seperti motor servo, selenoid, penampil, dan buzzer. Modul NodeMCU digunakan untuk mengirimkan hasil rekam data pengguna ruangan yang teridentifkasi dari sensor sidik jari ke web database melalui jaringan internet..

Blok keluaran (Output) menggunakan komponen Motor Servo sebagai aktutor untuk membuka dan menutup pintu, penampil dengan LCM1602 IIC dan LCD 16x2. Selain itu blok output juga menggunakan Relay dan Solenoid untuk menutup pintu dan Buzzer sebagai indikator apabila terdapat user atau seseorang yang tidak berhak masuk ke dalam ruangan. Skematik rangkaian secara keseluruhan dari alat yang dirancang diperlihatkan gambar 6. 


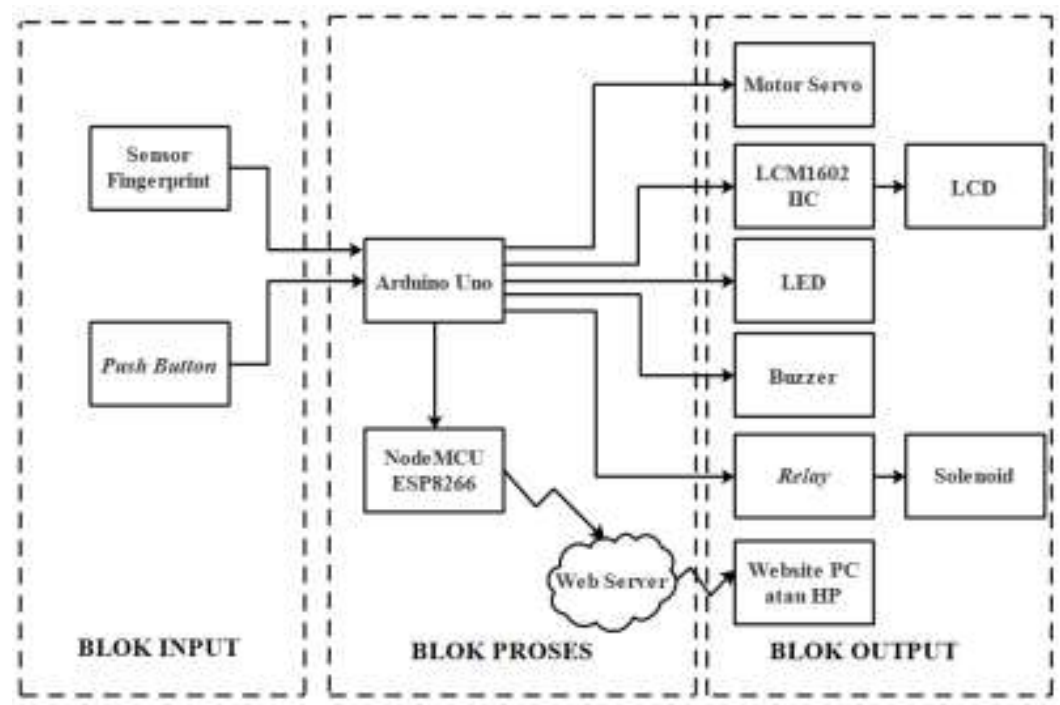

Gambar 5. Blok Diagram Rancangan Alat Telemonitoring Keamanan Ruangan Berbasis IOT

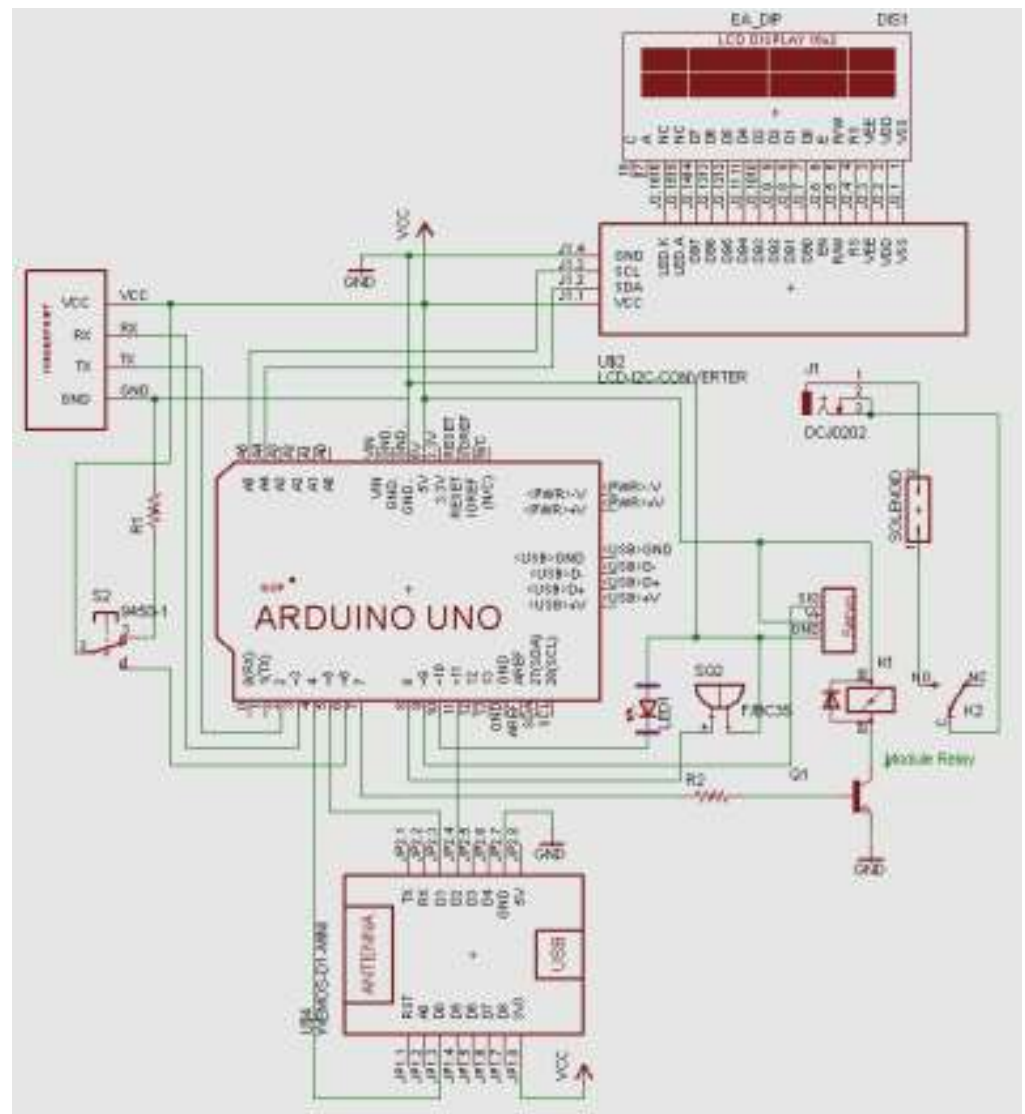

Gambar 6. Rangkaian Keseluruhan "Rancang Bangun Alat Keamanan Ruangan Menggunakan Sidik Jari Berbasis IOT" 


\subsection{Perancangan Perangkat Lunak}

Pada gambar 7 merupakan gambar diagram alir rancangan program yang dijalankan oleh arduino uno. Pada kondisi sensor sidik jari akan mengidentifikasi sidik jari user, apabila sidik jari sesuai maka layar lcd akan menampilkan "sidik jari diterima". Relay akan mengaktifkan solenoid untuk membuka kunci, dan servo akan bergerak untuk membuka pintu dengan sudut $90^{\circ}$. Proses selanjutnya pintu akan menutup secara otomatis dan penampil LCD akan menampilkan "pintu tertutup", dan relay akan mengaktifkan solenoid untuk mengunci pintu. Apabila sidik jari user yang dimasukan belum terdaftar maka layar lcd akan menampilkan "sidik jari ditolak", LED merah menyala dan buzzer akan menyala sebagai alarm.

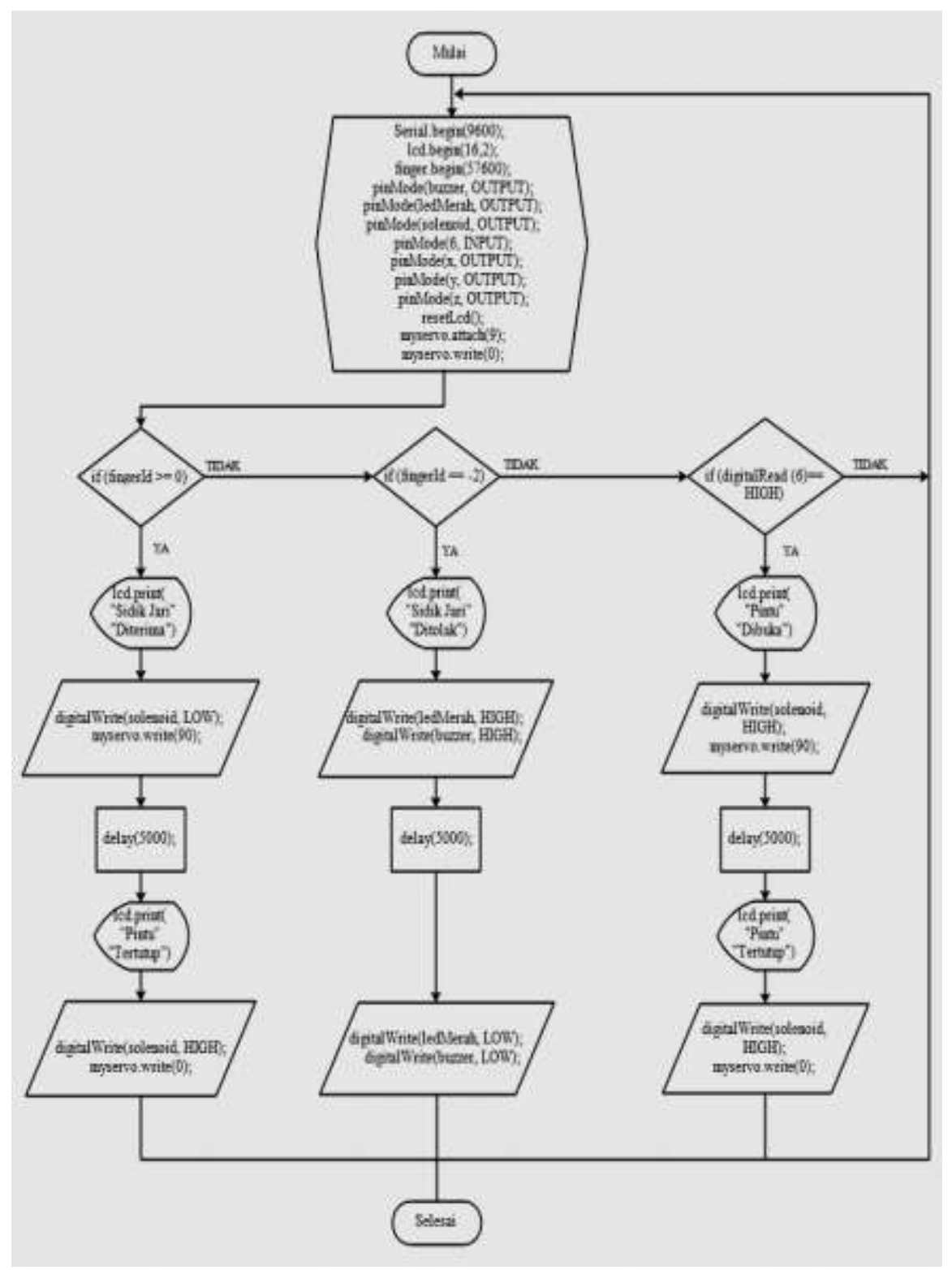

Gambar 7. Diagram Alir Rancangan Alat Telemonitoring Keamanan Ruangan Berbasis IOT 


\section{PEMBAHASAN}

\section{Pengujian Sensor Sidik Jari ZFM20}

Pengujian pada sensor sidik jari dilakukan untuk mengetahui proses verifikasi. Sebelum melakukan verifikasi terlebih dahulu dilakukan proses penyimpanan sidik jari ke dalam template sensor sidik jari ZFM20. Untuk proses penyimpanan sidik jari dinamakan enroll yang ditunjukan gambar 8.

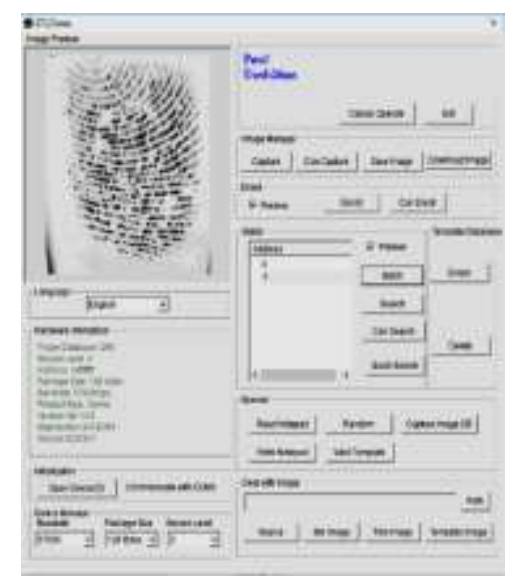

Gambar 8. Proses Verifikasi Sidik Jari Berhasil Pada SFG Demo

Apabila proses verifikasi tidak berhasil maka sensor sidik jari akan menolak akses terhadap pengguna. Proses verifikasi yang ditolak disebabkan sidik jari yang dimasukan tidak terdapat dalam template sensor. Proses verifikasi yang ditolak dapat dilihat pada gambar 9.

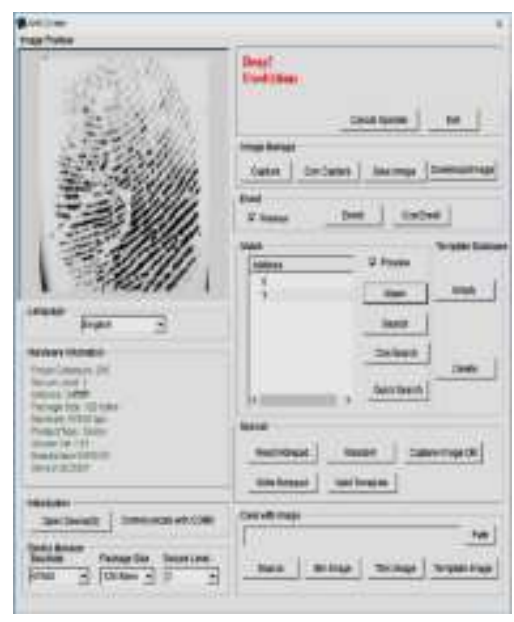

Gambar 9. Proses Verifikasi Sidik Jari Gagal Pada SFG Demo

\section{Pengamatan Dilakukan Pada Saat Sidik Jari Terdaftar}

Pengamatan ini dilakukan pada saat sidik jari yang ditempelkan pada optical fingerprint sudah terdaftar pada template untuk mengetahui tegangan pada saat kondisi sidik jari benar. 
Jurnal Electro Luceat [November] [2020]

Tabel 1 Hasil Pengamatan Pada Sensor Sidik Jari Sudah Tersimpan

\begin{tabular}{|c|c|c|c|c|}
\hline Penguji & $\begin{array}{c}\text { Tesansas } \\
\text { Motor Siervo } \\
\text { Pin De } \\
\text { (Volt) }\end{array}$ & $\begin{array}{c}\text { Treanuas } \\
\text { Relay } \\
\text { Pin D7 } \\
\text { (Voli) }\end{array}$ & $\begin{array}{l}\text { Teranzas } \\
\text { Solenoid } \\
\text { Pin No } \\
\text { (Voll) }\end{array}$ & Keteranuan \\
\hline 1 & 4.43 & 4,47 & 0 & Pintu Tersutup \\
\hline 2 & 0,07 & 0 & 12 & Riatu Terbuka \\
\hline
\end{tabular}

Berdasarkan Tabel 1 merupakan hasil pengamatan untuk mendapatkan nilai tegangan dari motor servo, relay, dan solenoid. Pengujian ini dilakukan saat sensor sidik jari yang ditag sudah terdaftar dengan melakukan pengukuran mengunakan multimeter untuk mendapatkan nilai tegangan di masing-masing komponen yaitu, kketika kondisi pintu tertutup motor servo pada titik ukur pin D9 sebesar $4.43 \mathrm{~V}$, relay di titik ukur pin D7 sebesar $4.47 \mathrm{~V}$, solenoid di titik NO sebesar $0 \mathrm{~V}$. sedangkan pada saat keadaan pintu terbuka tegangan yang diperoleh motor servo sebesar 78.5 $\mathrm{mV}$, relay sebesar $0 \mathrm{~V}$, dan solenoid sebesar $12 \mathrm{~V}$.

\section{Pengamatan Dilakukan Pada Saat Sidik Sidik Jari Tidak Terdaftar}

Pengamatan ini dilakukan untuk mengetahui output pada saat kondisi sidik jari yang ditempelkan pada optical fingerprint yang belum terdaftar.

Tabel 2 Hasil Pengamatan Pada Sidik Jari Belum Terdaftar

\begin{tabular}{|c|c|c|c|}
\hline Reassil & $\begin{array}{c}\text { Teanuas } \\
\text { TED } \\
\text { Pin Dio } \\
\text { CVolo }\end{array}$ & $\begin{array}{l}\text { Tezausze } \\
\text { Burseer } \\
\text { Pin Dos } \\
\text { CVotes }\end{array}$ & Ketecamsan \\
\hline 1 & o & 0 & $\begin{array}{l}\text { LED dan Buzzer } \\
\text { OFF }\end{array}$ \\
\hline 2 & a & 2,17 & $\begin{array}{c}\text { LED dan Buzzer } \\
\text { ON }\end{array}$ \\
\hline
\end{tabular}

Berdarkan tabel 2 pengamatan dilakukan pada saat sensor sidik jari yang ditag belum terdaftar. fungsi dari LED dan buzzer pada alat ini yaitu sebagai indikator. pada pengujian ini untuk mendapatkan nilai tegangan pada saat kondisi ON dan OFF. Ketika kondisi ON, LED pada titik ukur pin D10 sebesar $2 \mathrm{~V}$ dan buzzer dititik ukur pin D8 sebesar $2.17 \mathrm{~V}$, Sedangkan saat kondisi OFF LED sebesar $0 \mathrm{~V}$ dan buzzer sebesar $0 \mathrm{~V}$.

\section{Pengamatan Tampilan Pada LCD}

Dalam pengujian kali ini akan mengaati tampilan LCD pada saat kondisi awal prototipe dihidupkan. Pada saat sidik jari ditempelkan ke optical fingerprint yang sudah tersimpan, pada saat kondisi sidik jari yang ditempelkan ke optical fingerprint yang belum tersimpan, dan saat push button ditekan.

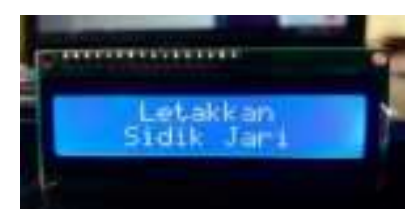

Gambar 10. Tampilan LCD saat kondisi awal 


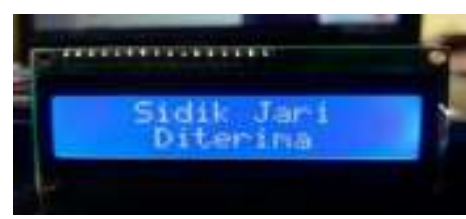

Gambar 11. Tampilan LCD saat sidik jari yang ditempelkan sudah tersimpan

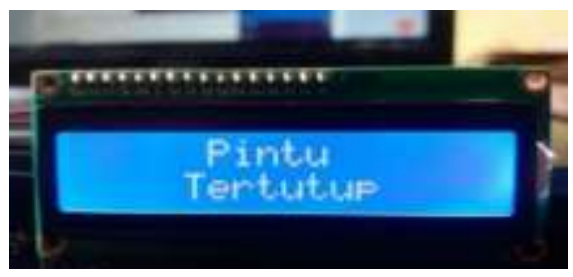

Gambar 12. Tampilan LCD saat pintu tertutup

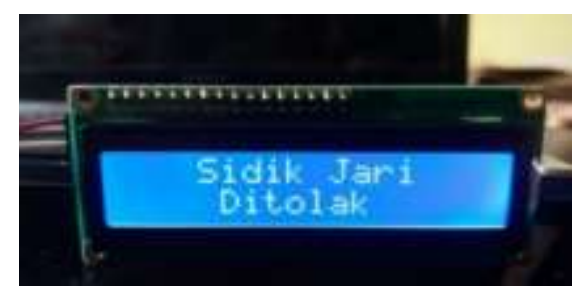

Gambar 13. Tampilan LCD saat sidik jari yang ditempelkan tidak terdaftar

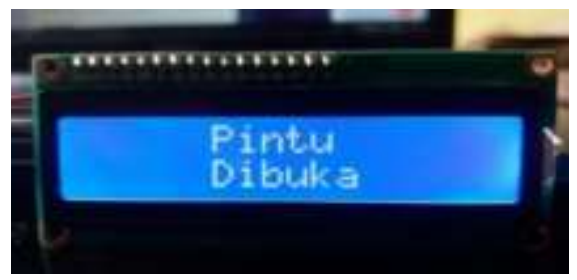

Gambar 14. Tampilan LCD saat push button ditekan

Pada gambar 14 merupakan tampilan LCD saat push button ditekan keadaan ini dilakukan pada saat pengguna berada di dalam ruangan untuk membuka pintu dengan menggunakan komponen push button dan LCD akan mendapatkan keluaran pada saat push button ditekan maka LCD akan menampilkan pada baris pertama dan kedua menampilkan tulisan "Pintu Dibuka" dan pintu akan tertutup secara otomatis dengan delay 5 detik untuk memberikan keluaran ke motor servo untuk menggerkan pintu ke posisi awal. Dan LCD akan menampilkan "Pintu Tertutup" seperti pada gambar 15 .

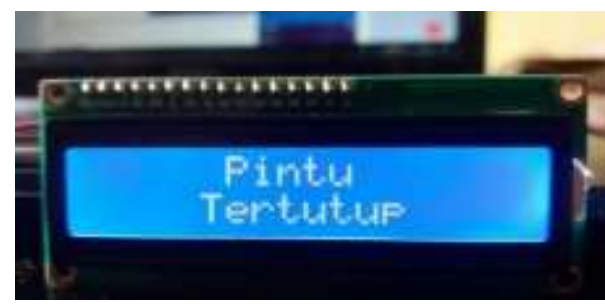

Gambar 15. Tampilan LCD Pintu Tertutup

\section{Pengujian Lama Waktu Proses Kerja Alat}

Pengujian ini digunakan untuk mengetahui delay waktu dari proses sensor pendeteksian sidik jari hingga informasi masuk dalam tampilan di website. Pengukuran waktu menggunakan 
perangkat stopwatch. Hasil pengujian ditampilkan seperti tabel 3. Berdasarkan lima pengujian, bahwa lama waktu proses kerja alat rata-rata sebesar 2,25 detik.

Tabel 3 Hasil Pengujian Lama Waktu Proses Kerja Alat

\begin{tabular}{|c|c|c|c|}
\hline Penguian & $\begin{array}{c}\text { Waktu } \\
\text { Peuguian }\end{array}$ & $\begin{array}{c}\text { Proses Pengiriman } \\
\text { Informasi Ke Website } \\
\text { (detik) }\end{array}$ & $\begin{array}{c}\text { Proses Refresh } \\
\text { Website } \\
\text { (detik) }\end{array}$ \\
\hline 1 & 07.00 & 7,29 & 2,25 \\
\hline 2 & 07.05 & 8,73 & 2,25 \\
\hline 3 & 07.10 & 9,04 & 2,25 \\
\hline 4 & 07.15 & 6,48 & 2,25 \\
\hline 5 & 07.20 & 7,23 & 2,25 \\
\hline \multicolumn{2}{|c|}{ Jumlah Rata-Rata } & 7,754 & 2,25 \\
\hline
\end{tabular}

\section{Pengamatan Tampilan Pada Website}

Pada pengujian ini merupakan tampilan website setelah modul wifi menerima masukan dari sensor sidik jari yang mendeteksi sidik jari, dan akan melalukan pemrosesan dengan modul wifi Nodemcu ESP8266 yang akan mengirimkan data informasi ke dalam tampilan website. Untuk melihat tampilan pada website dengan memasukan alamat http://homeguard.000webhostapp.com/index.php, maka akan muncul tampilan seperti pada gambar 16 .

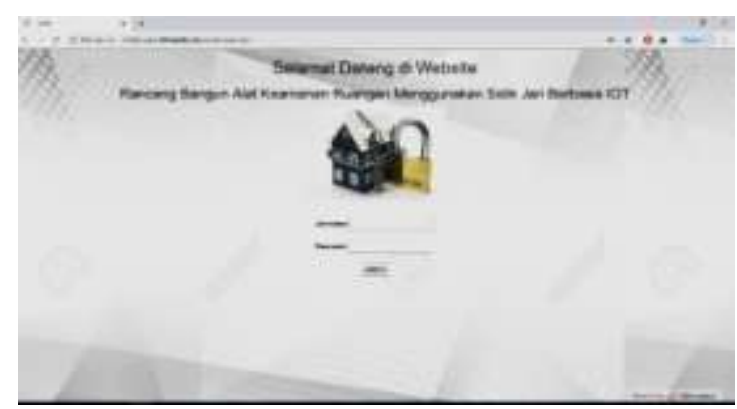

Gambar 16. Tampilan Home website

Pada gambar 16 merupakan tampilan pertama pada website admin harus memasukan username dan password terlebih dahulu kemudian di submit maka website akan menampilkan data informasi seperti yang ditunjukan pada gambar 17.

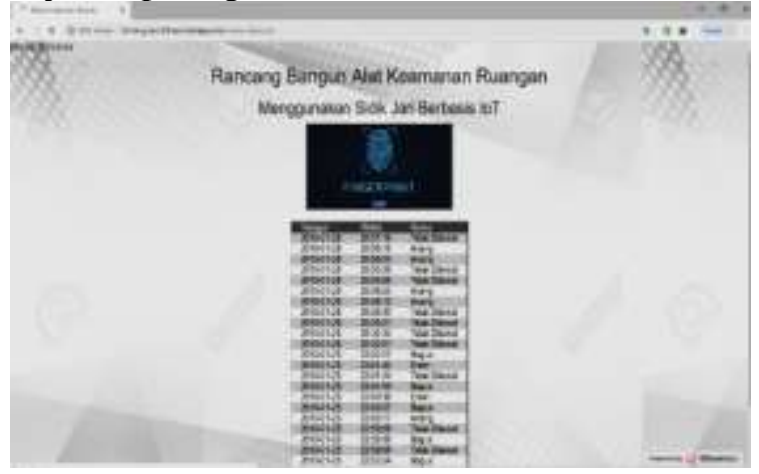

Gambar 17. Tampilan database pada Website

\section{Tampilan Website Saat Kondisi Sensor Mendeteksi Sidik Jari}

Pada tampilan website ini merupakan kondisi sensor saat mendeteksi sidik jari, jika sidik jari yang di tag sudah terdaftar maka website akan menampilkan "nama, waktu dan tanggal" sesuai dengan pemilik sidik jari. Dan apabila sidik jari yang di tag belum tedaftar maka website akan 
menampilkan "Sidik Jari tidak dikenal". Berikut adalah gambar tampilan website saat sidik jari yang di tag sudah terdaftar, yang ditunjukan pada gambar 18 .

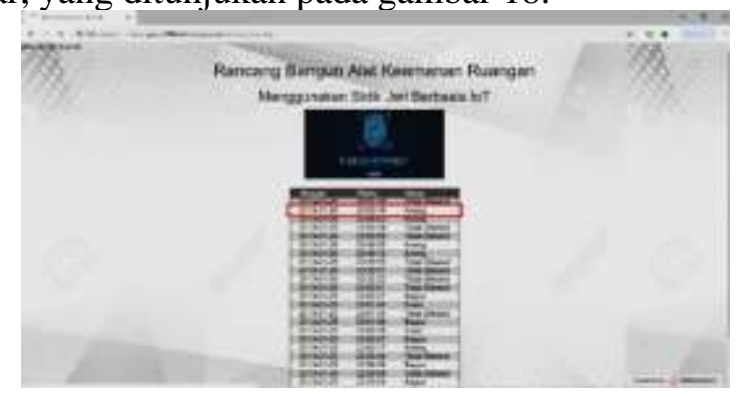

Gambar 18. Tampilan Website Yang Terdaftar

Pada gambar 18 merupakan tampilan website saat sidik jari yang di tag pada optical fingerprint sudah terdaftar. Website akan menampilkan data tanggal, waktu dan nama, apabila sidik jari yang ditag sudah terdapat pada template sensor maka pada kotak nama akan memunculkan nama pemilik sidik jari tersebut. Untuk tampilan pada website saat sidik jari yang di tag tidak terdaftar ditunjukan pada gambar 19.

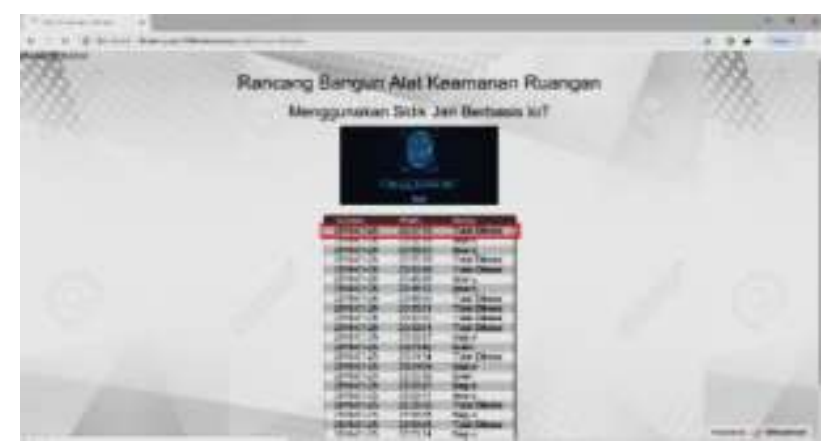

Gambar 19. Tampilan Website Yang Tidak Terdaftar

\section{KESIMPULAN}

Berdasarkan hasil penelitian yang dilakukan maka disimpulkan bahwa Rancang Bangun Alat Keamanan Ruangan Menggunakan Sidik Jari Berbasis IOT dapat bekerja sesuai dengan tujuan, yaitu:

1. Penelitian ini telah berhasil merancang dan membuat prototipe sistem monitorinng keamanan ruangan dengan identifikasi sidik jari menggunakan jaringan internet untuk proses tranfer data pada web database untuk rekam data pengguna ruangan yang ditampilkan pada website dengan alamat http://home-guard.000webhostapp.com/index.php

2. Alat dirancang dan dibangun menggunakan sensor sidik jari dan push button sebagai blok input, Arduino uno dan nodemcu esp8266 sebagai blok proses, motor servo, relay, solenoid dan LCD 16x2 sebagai output yang akan dihubungkan untuk membentuk sebuah rangkaian.

3. Berdasarkan pengujian alat ini telah dapat mendeteksi sidik jari baik yang sudah terdaftar maupun yang belum terdaftar. Hasil pengujjian delay waktu dari proses sensor pendeteksian sidik jari hingga informasi masuk dalam tampilan di website rata-rata sebesar 2,25 detik.

\section{DAFTAR PUSTAKA}


[1] Pratama, dan Sapto, H. 2015. RFID Sebagai Pengaman Pintu Laboratorium Jurusan Teknik Elekro. Semarang. Universitas Negeri Semarang. . [Online] Tersedia di. https://lib.unnes.ac.id/21850/ [diakses pada 30 Oktober 2019]

[2] Socaningrum, JF. Syafei, WA, dan Darjat. 2019. Implementasi Teknologi RFID pada Sistem Pintu Geser Otomatis sebagai Akses Masuk dalam Sistem Multi Akses Kartu Mahasiswa. [Online] Tersedia di https://ejournal3.undip.ac.id/index.php/transient/article/download/4479/4304 [diakses pada 3 Maret 2019] Rivaldo, R. Bustami, I., Siswanto, I. 2020 Perancangan Keamanan Pintu Gudang Menggunakan Rfid Dan Kamera Berbasis Raspberry Pi (Studi Kasus : Gudang V-Tech Jambi). Jurnal Ilmiah Mahasiswa Teknik Informatika Vol.2, No.2: 96-106

[3] Usman. Rahmansyah, A. Apriadi, N. 2017. Rancang Bangun Pagar Otomatis dengan Finger Print Berbasis Mikrokontroller JTT (Jurnal Teknologi Terapan). [Online] Tersedia di https://www.researchgate.net/publication/326807685_Rancang_Bangun_Pagar_Otomatis_den gan_Finger_Print_Berbasis_Mikrokontroller[diakses pada 14 Maret 2020]

[4] Siswanto, A. , Efendi, A., Yulianti, A. 2018. Alat Kontrol Akses Pintu Rumah dengan Teknologi Sidik Jari di Lingkungan Rumah Pintar dengan Data yang di Enkripsi. Jurnal Penelitian Pos dan informatika. [Online] Tersedia di https://www.researchgate.net/publication/331400760_ALAT_KONTROL_AKSES_PINTU _RUMAH_DENGAN_TEKNOLOGI_SIDIK_JARI_DI_LINGKUNGAN_RUMAH_PINTAR _DENGAN_DATA_YANG_DI_ENKRIPSI[diakses pada 11 Januari 2020]

[5] Asthon, K. 2009. That Internet of Things' Thing: In the real world, things matter more than ideas. [Online] Tersedia di http://www.rfidjournal.com/articles/view?4986, [diakses pada 17 Januari 2020]

[6] Tim Zhiantec, Hangzhou Zhian Technologies Co.,Ltd. 2020. ZFM-20 Series Fingerprint Identication Module. [Online] Tersedia di https://cdnshop.adafruit.com/datasheets/ZFM+user+manualV15.pdf, 2008, [diakses pada 22 mareti 2020]

[7] _ 2015. Arduino Uno. [Online] Tersedia di: http://arduino.cc/en/Main/ ArduinoBoardUno[diakses pada 13 Desember 2019]

[8] Tim Einstronik. Introduction To NodeMCU ESP8266 Devkit v1.0., [Online] Tersedia di www.einstronic.com [diakses pada 12 Februari 2020]

[9] Kadir, Abdul., 2013. Panduan praktis mempelajari aplikasi mikrokontroler dan pemrogramannnya menggunakan arduino. Jakarta : Andi Publisher.

[10] Siddharth,, 2019. I2C Protocol (2-Wire Interface), [Online] Tersedia di http://embedjournal.com/two-wire-interface-i2c-protocol-in-a-nut-shell/. [diakses pada 4 Januari 2020] 